\title{
Construção e avaliação do desempenho de três abanadoras de sementes
}

\author{
José G. da Silva ${ }^{1}$ \& Dino M. Soares ${ }^{1}$
}

\begin{abstract}
RESUMO
Os métodos de trilhamento das plantas não proporcionam grãos limpos, em condições de serem comercializados, semeados ou armazenados. É necessário que passem por um processo de limpeza com o fim de eliminar os fragmentos dos próprios grãos, detritos vegetais, folhas e pedaços de hastes. Os processos comuns de limpeza são pouco eficientes e os mais sofisticados podem não estar ao alcance de pequenos produtores. Objetivou-se, com este trabalho, construir três abanadoras e avaliar seu desempenho em sementes de arroz. Uma abanadora é provida de ventilador acionado a pedal; a outra possui ventilador acionado por motor elétrico e a terceira possui ventilador e peneiras movimentados por motor elétrico. Foram abanadas sementes com diferentes teores de impureza e em diferentes taxas de alimentação das máquinas. As abanadoras apresentaram maior eficiência de limpeza nas sementes com menor teor de impureza e na menor taxa de alimentação das máquinas. A eficiência foi considerada adequada para as sementes que possuíam até $4 \%$ de impureza antes da abanação. Com $6 \%$ de impureza, as sementes devem ser abanadas por três vezes, para ficarem com menos de $1 \%$ de impureza. A perda de sementes pelas abanadoras foi desprezível.
\end{abstract}

Palavras-chave: Oryza sativa, limpeza de sementes, máquina

\section{Construction and performance evaluation of three seed blowers}

\begin{abstract}
Usually, the available methods to trash cereal seeds do not provide a clean product, as required for commercialization, seeding and storage. For this purpose it is necessary to submit the seed lot to a cleaning process to eliminate grain fragments and other contaminants such as soil and plant particles. Common processing procedures are not efficient and other methods available, more sophisticated, are not economically suitable for small farmers. The objective of this study was to construct three different blowers and evaluate their performance on rice: one provided with a foot operated fan; a second with an electric fan; and a third with electric fan and screeners. Seed lots with different degrees of impurities and different machine feeding rates were used. Greater operation efficiency was obtained for the least contaminated lot and smallest seeding rate. Efficiency was considered adequate for seed lots up to $4 \%$ contamination level. For $6 \%$ impurity, seed lots had to be blown three times to lower impurity level less than $1 \%$. Seed loss was not significant.
\end{abstract}

Key words: Oryza sativa, seed cleaning, machine 


\section{INTRODUÇÃO}

O beneficiamento refere-se às etapas de preparação das sementes para a comercialização, semeadura ou armazenamento compreendendo, em geral, a pré-limpeza, limpeza, classificação e melhoramento das qualidades físicas das sementes (Bragantini, 1999). De acordo com Toledo \& Marcos Filho (1977), os principais objetivos do beneficiamento englobam a remoção das impurezas que acompanham as sementes e a melhoria da qualidade, devido à eliminação de impurezas e de sementes rachadas, quebradas e danificadas por insetos.

Normalmente, após a colheita as sementes apresentam materiais indesejáveis, em quantidades apreciáveis, que precisam ser eliminados (Buitrago et al., 1991). Conforme Vaughan et al. (1976), material inerte e sementes fora de tamanho afetam o fluxo de sementes nas máquinas, inclusive nas semeadoras, favorecem a infestação de insetos e prejudicam a qualidade do armazenamento. Outras matérias estranhas, como semente de plantas daninhas e de outras plantas cultivadas, podem afetar a qualidade dos plantios subseqüentes. Puzzi (1977) afirma que as impurezas prejudicam, ainda, as sementes, por serem portadoras de quantidades expressivas de microrganismos e de umidade mais elevada, que favorece o desenvolvimento de fungos.

Segundo Vaughan et al. (1976), a qualidade das sementes está diretamente relacionada com as suas características hereditárias e com a capacidade do beneficiador em remover, nelas, as suas impurezas. Assim sendo, a qualidade das sementes é afetada pelo tipo de equipamento e pelo método de limpeza empregado no beneficiamento.

O beneficiamento é baseado nas diferenças de características físicas entre as boas sementes e as impurezas. Materiais que não diferem entre si não podem ser separados (Vaughan et al., 1976). Desta forma, as separações por tamanho (largura e espessura) são realizadas pela máquina de ventilador e peneiras, que remove as impurezas leves e os materiais indesejáveis maiores ou menores que o desejado (Ahrens \& Krzyzanowski, 1995). A separação por peso é realizada por mesa gravitacional (Carvalho \& Nagagawa, 1988) e por máquinas pneumáticas. Conforme Vaughan et al. (1976), muitos modelos e tipos de máquina, com uma vasta gama de capacidade, estão disponíveis ao beneficiador de sementes. Devidamente operados, esses equipamentos permitem remover contaminantes que diferem das sementes pelo tamanho, comprimento, forma, peso, textura da superfície, afinidade com líquido, cor e condutividade elétrica.

Os métodos de limpeza mais simplificados consistem na abanação das sementes, lançando-as contra o ar natural para que as impurezas mais leves sejam jogadas para fora da massa de sementes; no emprego de ventilador, acionado manualmente para movimentar o ar contra uma camada de sementes lançada para cima com auxílio de pás; e na utilização de máquina abanadora acionada também manualmente, provida de ventilador, moega e mecanismo de transmissão de movimento.

Conforme Puzzi (1977) o rendimento da abanadora é influenciado pelo tipo e pela quantidade de impurezas presen- tes na massa de sementes, sendo proporcional à razão inversa de impurezas, pelo fato da semente ter de passar várias vezes pelo processo de abanação, até se obter teor de impurezas aceitável. Segundo o autor, para se obter o melhor tipo na comercialização do produto é tolerável, em geral, um teor máximo de 1\% de impureza, em relação ao peso. Conforme o Ministério da Agricultura (Brasil, 1989), o percentual máximo de matéria estranha e de impureza admitido para o arroz em casca é de $2 \%$.

Na colheita de pequenas lavouras de arroz, normalmente o beneficiamento de sementes é realizado de forma manual, com o auxílio de peneiras, que apresenta baixa capacidade de trabalho. A possibilidade do uso de novos equipamentos fabricados com técnicas simples e com recursos de pequenas oficinas, poderá criar condições que permitirão, aos pequenos agricultores, aumentar a eficiência da sua mão-de-obra. Neste sentido, este trabalho teve como objetivo construir três modelos de abanadoras de sementes e avaliar seu desempenho na abanação do arroz, em função de diferentes teores de impureza nas sementes e taxas de alimentação das máquinas.

\section{MATERIAL E MÉTODOS}

O experimento foi conduzido na Embrapa Arroz e Feijão, em Santo Antônio de Goiás, GO, e constou da construção e da avaliação do desempenho no arroz de três abanadoras.

\section{Abanadora a pedal (A1)}

A abanadora a pedal tem, como principais componentes, um ventilador de pás, uma estrutura de suporte e um mecanismo de transmissão de movimento. O ventilador foi provido de um cilindro metálico de 300 mm de diâmetro contendo, no seu interior, um eixo de ferro de $19 \mathrm{~mm}$ de diâmetro e $700 \mathrm{~mm}$ de comprimento, com duas cruzetas unidas por quatro chapas transversais de madeira de $480 \mathrm{~mm}$ de comprimento e $100 \mathrm{~mm}$ de largura. No cilindro foi conectado um ducto para conduzir o vento até a massa de sementes que sai de uma moega; dentro do ducto colocou-se um mecanismo para regular o fluxo de vento, de forma a minimizar as perdas e melhorar a eficiência da limpeza das sementes, enquanto na parte inferior da moega foram instalados uma comporta regulável para controlar a vazão de sementes e um mecanismo rotativo acanalado para uniformizar a distribuição das sementes sobre o fluxo de ar produzido. O eixo do ventilador foi apoiado em dois mancais montados sobre uma estrutura metálica. A transmissão de movimentos para o ventilador foi feita por meio de um pedal colocado na parte inferior traseira da máquina, de uma biela de ferro de 320 mm de comprimento e de três polias, duas de $250 \mathrm{~mm}$ e uma de $70 \mathrm{~mm}$ de diâmetro, unidas por duas correias trapezoidais. A máquina possui $800 \mathrm{~mm}$ de comprimento, $700 \mathrm{~mm}$ de largura e $800 \mathrm{~mm}$ de altura (Figura 1A).

\section{Abanadora a motor (A2)}

O desenvolvimento deste equipamento objetivou melhorar a eficiência da abanação e aumentar a capacidade de trabalho em relação à abanadora A1. A abanadora A2 difere da A1 por 

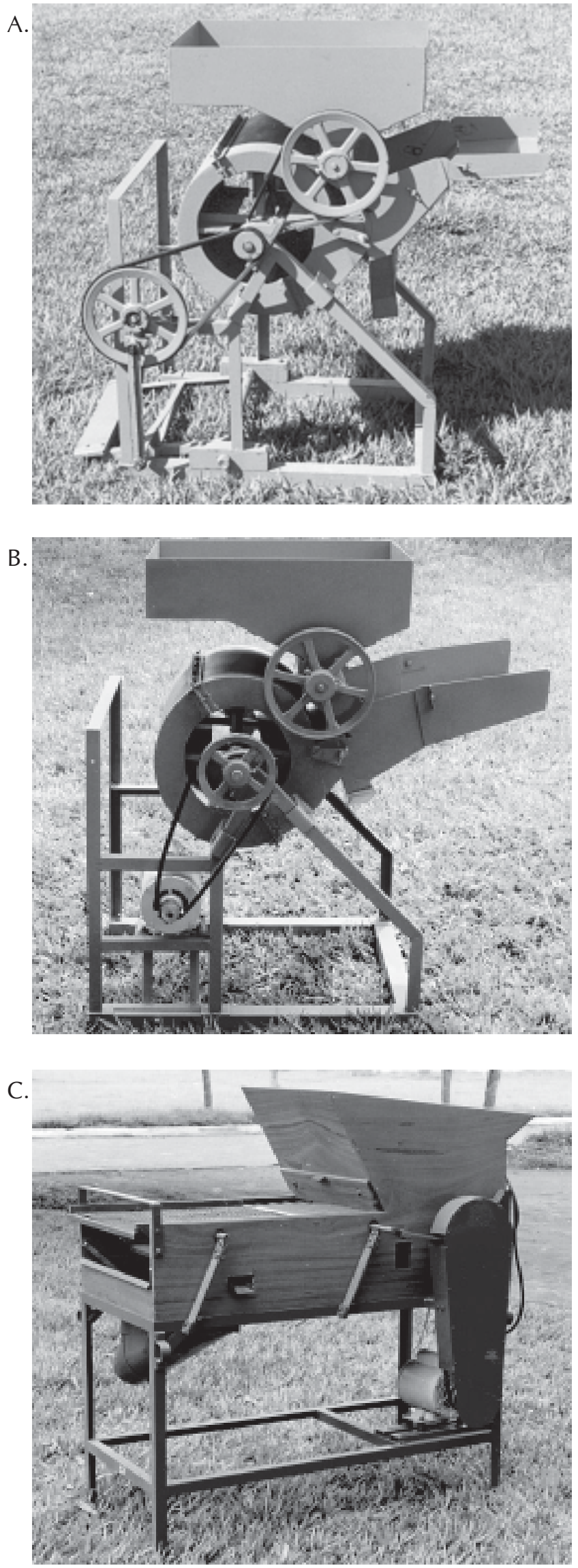

Figura 1. Abanadora de sementes com ventilador acionado a pedal: (A), com ventilador acionado a motor; (B) e com ventilador e peneira acionados a motor $(\mathrm{C})$ possuir um motor elétrico de 0,5 cv para acionar o ventilador, em substituição ao mecanismo a pedal (Figura 1B).

\section{Abanadora com motor e peneira (A3)}

A construção da A3 foi baseada num projeto do IRRI (1978) e teve o objetivo de melhorar a eficiência de limpeza das sementes em relação às abanadoras A1 e A2. A máquina possui, como componentes principais, uma moega; um regulador de vazão de sementes; um ventilador; peneiras, com movimento alternativo, para arroz, feijão, milho e soja; uma bica de ensacamento e um motor elétrico de 0,5 cv. A máquina tem $1200 \mathrm{~mm}$ de comprimento, $700 \mathrm{~mm}$ de largura e $1200 \mathrm{~mm}$ de altura (Figura 1C).

O delineamento experimental foi o inteiramente casualizado, com quatro repetições, em esquema fatorial 3 x 3 x 3 . Os fatores estudados foram: três modelos de abanadora; abanação de sementes com três teores de impurezas e a utilização de três taxas de alimentação de sementes nas máquinas.

Para cada tratamento foram preparadas porções de $30 \mathrm{~kg}$ de arroz da cultivar Formoso, contendo 2 (P2); 4 (P4) e 6\% (P6) de impurezas, formadas por casca e pedaços de folhas e de colmos do arroz. As porções foram colocadas nas moegas das três máquinas, reguladas para proporcionar três diferentes taxas de alimentação de sementes. As taxas (T) foram definidas em ensaios preliminares, regulando-se a abertura do registro da moega em 10 (T1), 15 (T2) e 20 mm (T3). As abanadoras foram operadas por duas pessoas, para proporcionar um trabalho ritmado de abastecimento e de ensacamento das sementes. As velocidades médias de rotação empregadas no ventilador das máquinas foram de $500 \mathrm{rpm}$ para A1 e A2 e de $600 \mathrm{rpm}$ para A3.

Durante a operação foi colocada, na descarga das abanadoras, uma bandeja para coletar as sementes lançadas com as impurezas para fora da máquina. As sementes recolhidas foram consideradas perdidas e sua massa foi expressa em porcentagem do total de sementes. A eficiência de limpeza foi calculada relacionando-se a quantidade de impureza na massa de sementes depois da operação de abanação com a existente antes. A capacidade de trabalho foi medida durante a operação de limpeza de $30 \mathrm{~kg}$ de sementes. Em cada ensaio, o arroz foi abanado em duas operações, sendo que os resultados de impureza extraídas da massa de sementes e as perdas de sementes corresponderam à soma dos valores e os de capacidade de trabalho, ao valor médio das duas operações.

\section{RESULTADOS E DISCUSSÃO}

A eficiência da abanação foi afetada pelo tipo de máquina abanadora, pela quantidade de impureza e pela taxa de alimentação de sementes nas máquinas (Tabela 1). Em termos percentuais, a redução de impureza das sementes, em uma ou em duas abanações, foi significativamente superior na operação da máquina A2, seguida das máquinas A1 e A3. A abanadora A2 foi mais eficiente na limpeza do arroz devido, provavelmente, à velocidade mais ritmada do seu ventilador, proporcionada pelo motor elétrico em relação ao sistema de 
acionamento a pedal da A1 ou à ausência de peneiras. Estas últimas podem ter dificultado o arraste das impurezas finas pelo vento para fora da máquina, como na A3.

A redução de impurezas foi maior quando seu teor na massa de semente era menor, ou seja, de $2 \%$. Nos teores de 4 e $6 \%$, a eficiência das máquinas foi semelhante porém, ao se considerar $1 \%$ como percentual aceitável de impurezas nas sementes, constata-se que são necessárias uma ou duas operações de abanação para o arroz com $2 \%$ e com $4 \%$ de impurezas, respectivamente. Nas sementes com 6\% de impurezas, as duas operações de abanação não foram suficientes, de vez que reduziram as impurezas para apenas $1,4 \%$, indicando a necessidade de mais operações de abanação.

A eficiência de limpeza foi influenciada significativamente pela taxa de alimentação de sementes nas máquinas. A redução de impureza foi maior ao se utilizar a menor abertura do registro de vazão de semente $(10 \mathrm{~mm})$ e diminuiu à medida que aumentava a taxa de alimentação.

A eficiência de limpeza do arroz interagiu com o tipo de máquina e com o percentual de impureza nas sementes (Figura 2 A). A máquina A2 apresentou maior eficiência de limpeza em relação às demais máquinas, somente na abanação das sementes com $2 \%$ de impureza, não diferindo das máquinas A1 e A3 nas sementes com 6 e 4\%, respectivamente. A interação dos fatores ainda mostra que, ao contrário das máquinas A2 e A3, a máquina A1 indicou eficiência mais baixa na limpeza do arroz com $2 \%$ de impureza, fato este que pode estar associado às variações na velocidade de giro no ventilador, causadas pelo pedal de acionamento.

Ocorreu interação significativa dos resultados de eficiência de limpeza, em função do tipo de abanadora e da taxa de alimentação de sementes (Figura 2 B). Em uma ou em duas operações de abanação, a máquina A2 somente foi mais

Tabela 1. Eficiência de limpeza do arroz proporcionada por uma operação, e eficiência de limpeza, perda de sementes e capacidade de trabalho, proporcionadas por duas operações de abanação em função do tipo de abanadora (A), do percentual de impureza (P) e da taxa de alimentação de sementes nas máquinas $(T)^{1}$

\begin{tabular}{|c|c|c|c|c|}
\hline \multirow{2}{*}{ Tratamento } & \multicolumn{2}{|c|}{ Eficiência de limpeza (\%) } & \multirow{2}{*}{$\begin{array}{c}\text { Perda de } \\
\text { sementes } \\
(\%)\end{array}$} & \multirow{2}{*}{$\begin{array}{l}\text { Capacidade } \\
\text { de trabalho } \\
\left(\mathrm{kg} \mathrm{h}^{-1}\right)\end{array}$} \\
\hline & Uma operação & Duas operações & & \\
\hline \multicolumn{5}{|l|}{ Abanadora² } \\
\hline $\mathrm{A} 1$ & 68,4 B & 77,7 B & $0,15 \mathrm{~A}$ & $342 \mathrm{C}$ \\
\hline $\mathrm{A} 2$ & $71,1 \mathrm{~A}$ & $83,6 \mathrm{~A}$ & $0,03 \mathrm{~B}$ & $474 \mathrm{~A}$ \\
\hline A3 & $66,0 \mathrm{C}$ & $76,4 \mathrm{C}$ & $0,03 \mathrm{~B}$ & $384 \mathrm{~B}$ \\
\hline \multicolumn{5}{|l|}{ Impureza } \\
\hline $\mathrm{P} 2=2 \%$ & $72,5 \mathrm{~A}$ & $84,0 \mathrm{~A}$ & $0,076 \mathrm{~A}$ & $424 \mathrm{~A}$ \\
\hline$P 4=4 \%$ & $67,1 \mathrm{~B}$ & $77,0 \mathrm{~B}$ & $0,092 \mathrm{~A}$ & $425 \mathrm{~A}$ \\
\hline$P 6=6 \%$ & 65,9 B & $76,0 \mathrm{~B}$ & 0,033 B & 359 B \\
\hline \multicolumn{5}{|c|}{ Taxa de alimentação ${ }^{3}$} \\
\hline $\mathrm{T} 1$ & $85,4 \mathrm{~A}$ & $90,8 \mathrm{~A}$ & $0,12 \mathrm{~A}$ & $189 \mathrm{C}$ \\
\hline $\mathrm{T} 2$ & $64,5 \mathrm{~B}$ & $76,6 \mathrm{~B}$ & $0,04 \mathrm{~B}$ & $442 \mathrm{~B}$ \\
\hline Т3 & $55,5 \mathrm{C}$ & $70,3 \mathrm{C}$ & $0,04 \mathrm{~B}$ & $578 \mathrm{~A}$ \\
\hline DMS & 1,3 & 1,1 & 0,04 & 9 \\
\hline CV & 3,3 & 2,5 & 119,0 & 3,8 \\
\hline
\end{tabular}

${ }^{1}$ Para cada variável, as médias seguidas pela mesma letra na vertical não diferem entre si pelo teste de Tukey, a $5 \%$ de probabilidade

${ }^{2} \mathrm{~A} 1$ - abanadora a pedal; A2 - abanadora a motor e A3 - abanadora com ventilador e peneira a motor ${ }^{3} \mathrm{~T} 1$, T2 e T3 - aberturas do registro da moega em 10,15 e $20 \mathrm{~mm}$, respectivamente
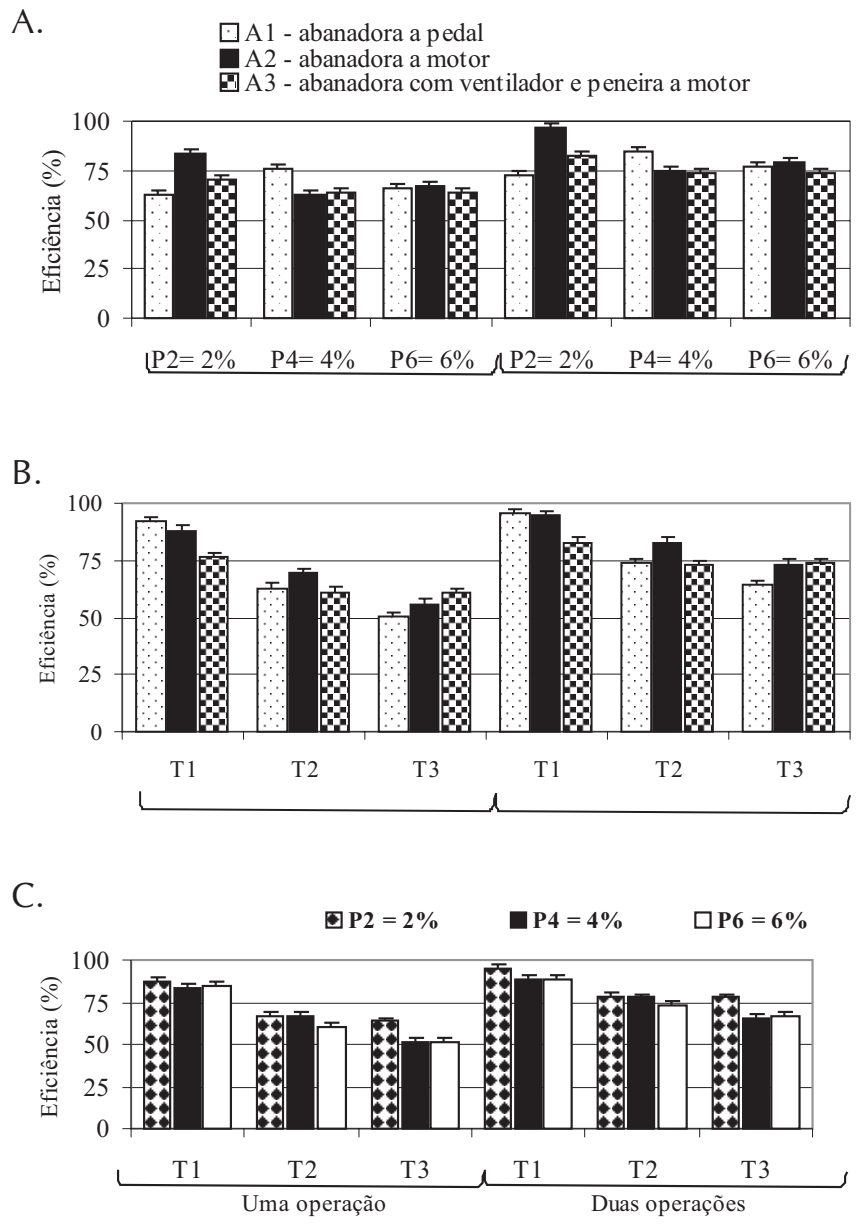

Figura 2. Eficiência de limpeza do arroz, proporcionada por uma ou por duas operações de diferentes abanadoras, (A) em função da porcentagem de impureza nas sementes, (B) da taxa de alimentação das máquinas e (C) da interação de percentual de impureza nas sementes com taxa de alimentação de sementes nas máquinas

eficiente que as outras na operação com a taxa de alimentação de sementes T2, ou seja, quando o registro dosador de sementes estava regulado com abertura de $15 \mathrm{~mm}$.

A eficiência de limpeza das sementes foi, ainda, afetada pela interação da porcentagem de impureza com a taxa de alimentação de sementes da máquina (Figura 2 C). Na regulagem de $15 \mathrm{~mm}$ do registro de vazão de sementes (T2), tanto em uma quanto em duas operações de abanação, a eficiência de limpeza proporcionada pelas máquinas A1 e A2 não diferiu estatisticamente.

A perda de sementes foi influenciada pelo tipo de máquina abanadora, pela quantidade de impureza e pela taxa de alimentação de sementes nas máquinas (Tabela 1). A perda média, em duas operações de abanação do arroz, foi inferior a $0,15 \%$. Este valor foi obtido na operação da máquina A1 que, devido ao uso de pedal, pode ter provocado produção desuniforme de vento, elevando o percentual de perda em relação às demais máquinas. As abanadoras A2 e A3 proporcionaram perda semelhante de sementes. A perda foi também influenciada pela quantidade de impureza na massa de sementes, sendo menor quando o percentual dela era de 6\%. Nas sementes com 2 e $4 \%$ de impureza, a perda foi estatisticamente 
semelhante. Constataram-se diferenças significativas entre os valores de perda, em função da taxa de alimentação de sementes das máquinas, sendo a taxa $\mathrm{T} 1$ a causadora dos maiores valores. As perdas verificadas em P4 e P6 ou em T2 e T3, não diferiram estatisticamente.

A perda de sementes em duas operações de limpeza do arroz, interagiu em função do tipo de máquina e da porcentagem de impurezas nas sementes (Tabela 2). A máquina A1 propiciou perda superior às demais máquinas somente na limpeza do arroz com $2 \%$ e $4 \%$ de impurezas. Os resultados indicam que a perda de arroz, em função dos teores de impurezas nas sementes, não variou nas operações das máquinas A2 e A3; entretanto, a máquina A1 apresentou mais perda de sementes quando o seu percentual de impurezas era de $4 \%$.

A perda de sementes também variou significativamente em função da interação do tipo de máquina com a taxa de alimentação de sementes (Tabela 2). Na taxa T3, a perda de arroz das três máquinas não diferiu significativamente. Por outro lado, a perda de arroz causada pelas abanadoras A2 e A3 não foi afetada pela taxa de alimentação, porém a perda em A1 foi maior na taxa T2, quando o registro dosador de sementes estava aberto em $15 \mathrm{~mm}$.

A capacidade de trabalho foi afetada pelo tipo de máquina, pela quantidade de impureza e pela taxa de alimentação de sementes (Tabela 1). O melhor desempenho foi proporcionado pela máquina $\mathrm{A} 2$, que superou estatisticamente as demais. A máquina A3 apresentou desempenho intermediário. O rendimento das máquinas, para se efetuar duas operações de abanação, variou de 342 a $474 \mathrm{~kg} \mathrm{~h}^{-1}$, e pode ser considerado adequado, principalmente ao ser comparado com os rendimentos obtidos com o método de abanação manual. A capacidade de trabalho decresceu a medida em que se aumentou o teor de impureza nas sementes de 4 para 6\%, porém com 2 e 4\% de impureza o rendimento das máquinas foi semelhante. Este fato pode estar relacionado à obstrução do registro da moega à passagem de sementes com $6 \%$ de impureza verificada durante os ensaios. Em relação à taxa de alimentação de

Tabela 2. Perda de arroz provocada por duas operações de diferentes abanadoras (A), em função da porcentagem de impureza (P) e da taxa de alimentação de sementes nas máquinas $(\mathrm{T})^{1}$

\begin{tabular}{cccc}
\hline & \multicolumn{3}{c}{ Abanadora $^{2}$} \\
\cline { 2 - 4 } Tratamento & A1 & A2 & A3 \\
\cline { 2 - 4 } Impureza & \multicolumn{3}{c}{ Perda de arroz (\%) } \\
P2 $=2 \%$ & $0,14 \mathrm{aB}$ & $0,04 \mathrm{bA}$ & $0,05 \mathrm{bA}$ \\
P4 $=4 \%$ & $0,25 \mathrm{aA}$ & $0,01 \mathrm{bA}$ & $0,02 \mathrm{bA}$ \\
P6 $=6 \%$ & $0,05 \mathrm{aC}$ & $0,03 \mathrm{aA}$ & $0,02 \mathrm{aA}$ \\
Taxa de alimentação & & & \\
T1 & & $0,06 \mathrm{bA}$ & $0,03 \mathrm{bA}$ \\
T2 & $0,28 \mathrm{aB}$ & $0,01 \mathrm{bA}$ & $0,02 \mathrm{bA}$ \\
T3 & $0,95 \mathrm{aA}$ & $0,01 \mathrm{aA}$ & $0,04 \mathrm{aA}$ \\
\hline DMS $=0,08$ & $0,07 \mathrm{aC}$ & & \\
\hline
\end{tabular}

${ }^{1}$ Para cada variável, as médias seguidas pela mesma letra minúscula na horizontal e maiúscula na vertical, não diferem entre si pelo teste de Tukey, a $5 \%$ de probabilidade;

${ }^{2} \mathrm{~A} 1$ - abanadora a pedal; A2 - abanadora a motor e A3 - abanadora com ventilador e peneira a motor. ${ }_{3}^{3} 1$, T2 e T3 - aberturas do registro da moega em 10,15 e $20 \mathrm{~mm}$, respectivamente
Tabela 3. Capacidade de trabalho de diferentes abanadoras em duas operações, em função das interações de porcentagem de impureza nas sementes (P) com tipos de abanadoras e com taxa de alimentação de sementes da máquina ${ }^{1}$

\begin{tabular}{|c|c|c|c|}
\hline \multirow[t]{3}{*}{ Tratamento } & \multicolumn{3}{|c|}{ Impureza } \\
\hline & $\mathrm{P} 2=2 \%$ & $\mathrm{P} 4=4 \%$ & $P 6=6 \%$ \\
\hline & \multicolumn{3}{|c|}{ Capacidade de Trabalho $\left(\mathrm{kg} \mathrm{h}^{-1}\right)$} \\
\hline \multicolumn{4}{|l|}{ Abanadora² $^{2}$} \\
\hline A1 & $372 \mathrm{aC}$ & $336 \mathrm{bc}$ & $316 c C$ \\
\hline $\mathrm{A} 2$ & $473 \mathrm{bA}$ & $529 \mathrm{aA}$ & $420 \mathrm{cA}$ \\
\hline A3 & $428 \mathrm{aB}$ & $411 \mathrm{bB}$ & $341 c B$ \\
\hline \multicolumn{4}{|c|}{ Taxa de alimentação ${ }^{3}$} \\
\hline $\mathrm{T} 1$ & $205 \mathrm{aC}$ & $199 \mathrm{aC}$ & $161 b c$ \\
\hline T2 & $476 \mathrm{aB}$ & $446 \mathrm{bB}$ & $406 \mathrm{cB}$ \\
\hline T3 & $594 \mathrm{bA}$ & $631 \mathrm{aA}$ & $510 \mathrm{cA}$ \\
\hline $\mathrm{DMS}=15$ & & & \\
\hline
\end{tabular}

'Para cada variável, as médias seguidas pela mesma letra minúscula na horizontal e maiúscula na vertical, não diferem entre si pelo teste de Tukey, a $5 \%$ de probabilidade.

${ }^{2} A 1$ - abanadora a pedal; $A 2$ - abanadora a motor e $A 3$ - abanadora com ventilador e peneira a motor. ${ }^{3} \mathrm{~T} 1, \mathrm{~T} 2 \mathrm{e} \mathrm{T} 3 \mathrm{-}$ - aberturas do registro da moega em 10, 15 e $20 \mathrm{~mm}$, respectivamente

sementes, verificou-se que, quanto maior a taxa, maior também foi a capacidade de trabalho das máquinas.

A capacidade de trabalho foi influenciada pela interação do tipo de máquina com a porcentagem de impureza nas sementes (Tabela 3). A máquina A2, ao contrário das demais máquinas, apresentou maior rendimento ao operar nas sementes com 4\% de impureza (P4), o que pode ser atribuído à maior ocorrência de obstruções à passagem do arroz pelo registro dosador da moega, formada ao acaso durante a aplicação do tratamento A2P2.

Verifica-se, na Tabela 3, que os resultados de capacidade de trabalho interagiram significativamente em função do percentual de impurezas e da taxa de alimentação de sementes. O desempenho das máquinas em sementes com $4 \%$ de impurezas foi igual ou superior ao obtido em sementes com $2 \%$ de impureza, quando foram empregadas as taxas de alimentação T1 e T3, respectivamente.

\section{CONCLUSÕES}

1. A abanadora com ventilador acionado a motor apresenta maior capacidade de trabalho que as demais máquinas providas de ventilador acionado a pedal, ou de ventilador mais peneira, acionados a motor.

2. A capacidade de trabalho das abanadoras é maior quando se utiliza maior abertura do registro de vazão de sementes e quando as sementes possuem menor quantidade de impureza.

3. A eficiência de limpeza nas abanadoras é maior quando as sementes estão com menos impurezas e quando a vazão das sementes da moega é menor.

4. A perda de sementes provocada pela operação das abanadoras é desprezível por ser inferior a $0,15 \%$.

5. A análise conjunta dos parâmetros avaliados (eficiência de limpeza, perda de sementes e capacidade de trabalho) indica a abanadora de arroz com ventilador acionado por 
motor elétrico de 0,5 cv como a de melhor desempenho técnico entre as máquinas ensaiadas.

\section{LITERATURA CITADA}

Ahrens, D. C.; Krzyzanowski, F. C. Separador em espiral e mesa de gravidade na qualidade fisiológica de sementes de soja. Informativo Abrates, Londrina, v.4, n.3, p.14-18, 1995.

Bragantini, C. Secagem e beneficiamento de sementes. In: Vieira, N. R. de A.; Santos, A. B. dos; Sant'Ana, E. P. (ed.). A cultura do arroz no Brasil. Santo Antônio de Goiás: Embrapa Arroz e Feijão, 1999. p.515-538.

Brasil. Ministério da Agricultura. Secretaria Nacional de Abastecimento. Normas de identidade, qualidade, embalagem e apresentação do arroz. Brasília: Secretaria Nacional de Abastecimento, 1989. 35p.
Buitrago, I. C.; Villela, F. A; Tillmann, M. A. A.; Silva, J. B. Perdas e qualidade de sementes de feijão beneficiadas em máquina de ventiladores e peneiras e mesa de gravidade. Revista Brasileira de Sementes, Brasília, v.13, n.2, p.99104, 1991.

Carvalho, N. M.; Nagagawa, J. Sementes: ciência, tecnologia e produção. 3.ed. Campinas: Fundação Cargill, 1988. 424p.

IRRI - International Rice Research Institute (Los Baños, Filipinas). IRRI portable grain cleaner: operator's manual. Los Baños: IRRI, 1978. 14p.

Puzzi, D. Manual de armazenamento de grãos: armazéns e silos. São Paulo: Agronômica Ceres, 1977. 405p.

Toledo, F. F. de; Marcos Filho, J. Manual das sementes: tecnologia de produção. São Paulo: Agronômica Ceres, 1977. 224p.

Vaughan, C. E.; Gregg, B. R.; Delouche, J. C. Beneficiamento e manuseio de sementes. Brasília: Agiplan, 1976. 195p. 